\title{
APRESENTAÇÃO: DOSSIÊ EDUCAÇÃO PATRIMONIAL
}

DOI

http://dx.doi.org/10.11606/issn.1980-4466.v14i27espp7-13

Organizadores

GABRIEL DE ANDRADE FERNANDES, UNIVERSIDADE DE SÃO PAULO,

SÃO PAULO, SÃO PAULO, BRASIL.

JOÃO LORANDI DEMARCHI, UNIVERSIDADE DE SÃO PAULO, SÃO PAULO,

SÃO PAULO, BRASIL.

SIMONE SCIFONI, UNIVERSIDADE DE SÃO PAULO, SÃO PAULO, SÃO PAULO, BRASIL.

Temática relativamente nova, desconhecida por muitas escolas e menosprezadas pelas instituições de patrimônio do Brasil, a Educação Patrimonial é, também, pouco presente na reflexão crítica que se faz nas universidades. Apesar disso, ela tem se multiplicado cada vez mais em suas práticas, ações e projetos pelo país afora, na forma de cartilhas, guias, exposições, folhetos, cadernos pedagógicos, proposições de jogos e atividades lúdicas. Se, por um lado, esse fato engrossa quantitativamente o campo de atuação, em contrapartida não traz necessariamente o significado de avanço qualitativo nas concepções, já que, muitas vezes, tais práticas são destituídas de fundamentação teórica mais consistente e, por isso, têm repetido abordagens educacionais defasadas, conservadoras e conteudistas. Nesse sentido, destaca-se a importância da constante reflexão crítica sobre as ações educativas, para evitar possível contradição entre uma proposta que, embora imbuída de boas intenções, possa ser, na prática, conservadora. 
A contradição existente entre essas diferentes situações no interior da Educação Patrimonial pode ser interpretada como consequência da intensa fragmentação existente neste campo, já que muitas iniciativas ficam isoladas em suas realidades locais e há, em vista disto, pouco diálogo e troca no sentido da construção coletiva de uma área de atuação. A dificuldade de sua consolidação vem da fratura interna que se instalou naquilo que poderíamos chamar de campo de convergência e articulação entre educação e patrimônio.

Pode-se situar a inauguração desta ruptura a partir da vinculação da expressão "educação patrimonial” a uma determinada metodologia, fato que decorreu das discussões apresentadas em um seminário no Museu Imperial de Petrópolis, em 1983. Mais tarde, já nos anos 1990, a publicação do Guia básico de educação patrimonial (HORTA; GRUNBERG; MONTEIRO, 1999) reafirmou essa mesma vinculação do termo a uma experiência, deixando de atentar para a existência de inúmeras outras metodologias possíveis, o que ampliou ainda mais o mal estar entre os profissionais que atuam nesse campo da educação e patrimônio.

Conforme alertou Mario Chagas (2006), essa afirmação também deixava de atentar para a historicidade do campo ao tomar pra si a expressão e circunscrevê-la a uma experiência do Museu Imperial. Assim sendo, gerou-se como desdobramento uma postura de recusa em usar o termo "educação patrimonial", surgindo e reafirmando-se, alternativamente, outras denominações em oposição a ela, tais como "educação para o patrimônio", "ação educativa", "ação museal". O que aconteceu, de fato, é que os esforços para a consolidação e renovação nessa área de atuação ficaram dispersos, apesar da existência de um elemento comum a todos, ou seja, a prática educativa mobilizando saberes em torno do patrimônio, da herança cultural e da memória coletiva.

É preciso reconhecer que a dispersão não tem contribuído para o avanço e superação das práticas tradicionais, nem permitido uma convergência de esforços no sentido de constituir uma fundamentação teórica e uma perspectiva epistemológica sobre esse campo. Nesse sentido, um problema comum às ações educativas tem sido o seu despreparo para lidar com as questões inerentes ao universo da educação. Muito centradas na preocupação em conceituar e apresentar o universo do patrimônio e da cultura, as iniciativas têm pecado no que diz respeito à tomada de posição em relação à educação, como se essa fosse um campo neutro. Ao contrário, é preciso lembrar que a 
educação é o locus privilegiado do enfrentamento político-ideológico, onde se confronta, também, um modelo de sociedade e um determinado papel do Estado. Esse enfrentamento se dá entre duas posições antagônicas, ou seja, entre aquela que vê a educação como instrumental para a reprodução da sociedade enquanto tal ou para a manutenção do establishment; ou aquela que a concebe como parte de um projeto de transformação social, de emancipação humana e libertação, conforme pensou Paulo Freire (2011; 2017).

Contrapor-se a essa fragmentação é, assim, estratégico para fazer avançar a discussão atual, construindo novos caminhos de atuação. Para isso, a universidade tem um papel fundamental como o lugar de centralidade da reflexão crítica e da pesquisa. É nessa perspectiva que a Revista CPC propõe o Dossiê Educação Patrimonial, trazendo artigos que buscam debater o campo da Educação Patrimonial abrindo novas perspectivas para o seu entendimento a partir de três questões fundamentais: a concepção das políticas públicas; o escopo das ações educativas; a educação como diálogo entre saberes.

No que diz respeito às políticas públicas no campo da Educação Patrimonial, Simone Scifoni, Cléo Alves Pinto de Oliveira e Sonia Rampim apresentam e debatem os traços mais gerais e os conflitos que caracterizam a sua constituição. No artigo que abre o dossiê, Simone Scifoni busca mostrar problematizar a ideia bastante difundida no senso comum, ou seja, "conhecer para preservar", mostrando que a origem de tal afirmação se encontra situada na tradição da instituição do patrimônio no país, nos anos 1930. Coloca em evidência, assim, os riscos de reproduzir esse ideário do passado no tempo presente, no que diz respeito à despolitização do debate. Cléo de Oliveira aborda o tema a partir de uma historiografia das políticas, situando os marcos, as continuidades e rupturas e as contradições em cada momento e explicita a problemática em torno da publicação do Guia básico de educação patrimonial, do Instituto do Patrimônio Histórico e Artístico Nacional (Iphan). Por sua vez, Sônia Rampim apresenta as linhas mestras de uma política que começa a ser redesenhada principalmente a partir de 2009, com a criação da Coordenação de Educação Patrimonial (Ceduc/Iphan), e que foi responsável pela renovação das ações institucionais. Como exemplos destacam-se tanto a implementação das Casas do Patrimônio como o fomento à articulação intersetorial que resultou em experiências com os programas Mais Educação e Extensão Universitária (ProExt), os quais incorporaram a 
temática de patrimônio nos diferentes segmentos da educação formal. Em um momento crítico de retrocessos nas políticas públicas, como o que o Brasil tem vivido, é mais do que necessário conhecer essas experiências, muitas das quais, lamentavelmente, estão sendo enfraquecidas e eliminadas.

O segundo conjunto de reflexões que os artigos trazem diz respeito à necessidade de repensar o escopo das ações de educação patrimonial, uma vez que frequentemente elas se voltam unicamente ao patrimônio institucionalizado, como é o caso do próprio Guia básico de educação patrimonial, que traz exemplos de atividades educativas voltadas exclusivamente a centros históricos e museus.

Nesse sentido, Simone Monteiro Silvestre Fernandes e Fernando Pascuotte Siviero trazem experiências de ações que buscam superar a visão do patrimônio como expressão da arquitetura de pedra e cal. Em Ouro Preto, Simone Fernandes nos mostra a importância social de projetos como o "Sou do morro - eu também sou patrimônio", que trabalhou na perspectiva da valorização de grupos sociais mais pobres, moradores dos morros, que não se viam pertencentes à própria cidade que se concebe como patrimônio. Fernando Siviero, por sua vez, apresenta a abordagem dos Territórios Educativos como um caminho a ser trilhado em projetos que pretendam superar o enfoque único no perímetro delimitado do centro histórico, concebendo a cidade em si mesma como um bem cultural. $\mathrm{O}$ autor ainda traz uma importante reflexão sobre o conceito de conscientização utilizado no campo do patrimônio. A partir da contribuição teórica de Paulo Freire, o autor explicita o sentido do termo como de desvelamento da realidade a partir da postura crítica a ela mesma, o que implica, necessariamente, uma problematização do patrimônio autoritariamente imposto como memória de todos. Ambos os autores nos apresentam projetos educativos pensados a partir do conceito ampliado de patrimônio cultural, superando, assim, a visão consagradora da arquitetura de pedra e cal. Nesse sentido, o artigo de Cléo de Oliveira também nos lembra do Projeto Interação, nos anos 1980, como um excelente exemplo de práticas voltadas à valorização da cultura local e que, entretanto, é pouco conhecido do público em geral.

Os artigos explicitam a necessidade de compreender a Educação Patrimonial como diálogo de saberes e não como imposição de um ideário pré-concebido. Átila Tolentino retoma a construção das políticas públicas para lembrar que, ao mesmo tempo que produzem abusos da memória, em contrapartida, elas são responsáveis por esquecimentos programados. Nestes 
termos, o autor propõe que o diálogo necessário na Educação Patrimonial tenha como ponto de partida um processo de construção coletiva, em vez daquilo que está dado e naturalizado como herança. Por sua vez, Samira Chahin volta sua discussão aos educadores, tensionando o que vem a ser o processo de formação continuada que concebe o professor em um recipiente inerte que deve absorver os conteúdos definidos pelos profissionais e especialistas. A autora lembra da necessidade de autonomia do pensamento e do diálogo no processo de formação do educador, para que este não transforme os professores em meros repetidores de discursos concebidos pelos especialistas, mas um sujeito problematizador das políticas de memória e capaz de reconhecer e compreender o seu patrimônio.

Compõem esta edição, também, artigos que apresentam e debatem experiências educativas inovadoras, que foram desenvolvidas em várias localidades do país e se destacam por proporem novos olhares e caminhos de abordagem, além de colocarem em destaque outros grupos sociais que foram sistematicamente ocultados na trajetória da preservação do patrimônio. Projetos relatados por Nivaldo Aureliano Léo Neto e Larissa Isidoro Serradela, por Maria Helena Bertolini Bezerra e Regina Célia Soares Bortoto e por Danilo Celso Pereira têm em comum o fato de colocarem em evidência a opção pelo trabalho de valorização da memória e das práticas culturais de grupos subalternos, tais como comunidades quilombolas, caiçaras, e operariado urbano.

Nivaldo Léo Neto e Larissa Serradela apresentam o trabalho realizado com uma comunidade quilombola-indígena do sertão nordestino, que se utilizou da metodologia dos inventários participativos proposta pelo Iphan. O projeto investiu na autonomia dos sujeitos, estimulando-os a contarem sua própria história e identificarem seu patrimônio, o que resultou em um processo de autovalorização da comunidade. Pelo seu mérito recebeu o Prêmio Rodrigo Melo Franco de Andrade, do Iphan, no ano de 2015, como uma iniciativa de excelência em gestão compartilhada do patrimônio.

Ações desenvolvidas por movimentos sociais são raramente encontradas no campo da Educação Patrimonial, ainda mais aquelas que combinam atuação em bairros periféricos e moradores de origem operária. Assim se apresenta o trabalho de Maria Helena Bezerra e Regina Bortoto, que coloca em evidência os esforços locais para a preservação de uma fábrica que é o elemento central em torno do qual se construiu uma memória de luta e organização dos trabalhadores. As autoras apresentam as articulações que 
envolveram a universidade pública, as escolas do bairro, o movimento social e grupos de jovens em uma iniciativa única de preservação de uma fábrica não pelo seu valor como um patrimônio industrial, mas verdadeiramente como um patrimônio operário e sindical.

A opção pela valorização das memórias coletivas das chamadas minorias ou de grupos sociais pouco representados nas políticas de patrimônio, como caiçaras, ribeirinhos, pescadores e quilombolas também se faz presente nas ações apresentadas por Danilo Pereira. O projeto Memórias Urbanas, ao trabalhar com o tombamento do centro histórico de Iguape, inverteu a lógica comum ao priorizar ações de reconhecimento dos saberes locais e de valorização dos moradores. Isso foi feito a partir da criação de espaços de diálogo e de troca entre diferentes gerações portadoras da memória coletiva.

Dentre as práticas inovadoras destaca-se, também, a experiência desenvolvida pela Rede Paulista de Educação Patrimonial (Repep), apresentada por Anaclara V. Antonini, Mariana Kimie S. Nito e Maryclea Carmona M. Neves, membros atuantes desse coletivo que tem como objetivo repensar as práticas e a discussão teórica nesse campo. As autoras apresentam a trajetória de formação do grupo, os desafios iniciais e a busca de um caminho próprio e inovador, evidenciando a importância de esforços coletivos sem os quais não se consegue renovar a Educação Patrimonial.

Por fim, encontram-se, ainda, relatos e discussões sobre as ações desenvolvidas no âmbito da Universidade de São Paulo (USP) em setores estratégicos do patrimônio, como é o caso da arqueologia, com a apresentação das ações do Museu de Arqueologia e Etnografia (MAE), e as experiências consolidadas da Base Avançada do Engenho dos Erasmos e do Centro de Preservação Cultural da USP. São ações que evidenciam as múltiplas e diferenciadas possibilidades de abordagem educativa em patrimônio cultural e que se mostram constantemente alimentadas na relação ensino-pesquisa-extensão que se realiza nessas unidades.

O desafio na construção de uma abordagem educativa para o patrimônio arqueológico é detalhada no artigo de Camilo de Mello Vasconcellos sobre a experiência do MAE. O autor destaca, em particular, a trajetória e os trabalhos do museu na produção de materiais pedagógicos especializados e inovadores, que têm como função aproximar a reflexão arqueológica de um público formado por jovens e crianças. Os kits educativos permitem 
desmistificar e, ao mesmo tempo, tornar mais concreta a compreensão do que vem a ser o trabalho da arqueologia.

A equipe da Base Avançada da USP, formada pelas professoras Vera Lucia Amaral Ferlini ${ }^{1}$ e Beatriz Pacheco Jordão, além dos educadores Rodrigo Christofoletti ${ }^{2}$ e André Müller de Mello, destaca os 12 anos de atuação dessa unidade, vinculada à Pró-Reitoria de Cultura e Extensão, que se situa no litoral paulista. A equipe vem desenvolvendo atividades educativas voltadas à compreensão do sítio arqueológico e o seu ambiente natural e, nesse sentido, mostra como educação ambiental e patrimonial podem ser realizadas de forma articulada em um diálogos de saberes. O Engenho dos Erasmos se apresenta como um museu a céu aberto que busca problematizar os sentidos atribuídos àquele bem cultural, bem como se constitui em um espaço educativo, de fruição e aproximação com a natureza.

Como fechamento do conjunto de textos, tem-se o artigo de Gabriel Fernandes abordando a trajetória das ações educativas realizadas pelo CPC em busca de inserção dessa unidade em um bairro central e de perfil popular, como o Bixiga. O autor procurou destacar como, ao longo do tempo, o $\mathrm{CPC}$ foi transformando e repensando a sua forma de atuar, o que o levou a desenhar ações educativas de caráter mais dialógico, superando a visão da casa como patrimônio-monumento reificado.

Finalizando, a perspectiva desta publicação é oferecer um conjunto de artigos reflexivos e de experiências e ações práticas como contribuição e ponto de partida na compreensão dos atuais desafios e das possibilidades deste novo campo denominado Educação Patrimonial. Busca-se, assim, colocar em evidência os esforços coletivos para a construção de um debate necessário.

1. Historiadora e diretora do órgão até o ano de 2018.

2. Historiador e servidor do órgão até 2018.

\section{REFERÊNCIAS}

CHAGAS, Mario. Educação, museu e patrimônio: tensão, devoração e adjetivação. Revista Eletrônica do Iphan, Brasília, DF, n. 3, fev. 2006. Disponível em: http://www.labjor.unicamp.br/ patrimonio/materia.php?id=145. Acesso em: 18 abr. 2019.

FREIRE, Paulo. Pedagogia do oprimido. Rio de Janeiro: Paz e Terra, 2011.

FREIRE, Paulo. Pedagogia da autonomia: saberes necessários à prática educativa. Rio de Janeiro: Paz e Terra, 2017.

HORTA, Maria de Lourdes Parreiras; GRUNBERG, Evelina; MONTEIRO, Adriane Queiroz. Guia básico de educação patrimonial. Brasília, DF: Iphan; Petrópolis: Museu Imperial, 1999. 